\title{
FISH analysis on spontaneously arising micronuclei in the ICF syndrome
}

\author{
M Stacey, M S Bennett, M Hulten
}

\begin{abstract}
The ICF syndrome is a rare disorder where patients show undercondensation of the heterochromatic blocks of chromosomes 1,9 , and 16 along with variable immunodeficiency. The undercondensation of the heterochromatic block appears to be restricted to a portion of PHA stimulated $T$ cells. Patients with this syndrome also show an increase in micronuclei formation. We have used dual colour FISH to investigate the chromosomal content of these micronuclei in PHA stimulated peripheral blood cultures, an EBV transformed $B$ cell line, and also micronuclei observed in vivo from peripheral blood smears.
\end{abstract}

Chromosome 1 appears to be present in a higher proportion of micronuclei compared to chromosomes 9 and 16 in both a PHA stimulated culture and an EBV transformed cell line. An 18 centromeric probe, not associated with the ICF syndrome, showed no signal in any of the micronuclei observed.

The implications from these observations are that the heterochromatic instability in the ICF syndrome is manifested not only in $T$ but also in $B$ cells and that it is present in vivo.

( $(\mathcal{M}$ Med Genet 1995;32:502-508)

The phenomenon of micronuclei formation has been widely used to detect the genotoxic effects of environmental mutagens ${ }^{1}$ and infectious agents ${ }^{2}$ although high spontaneous levels are also known to exist in patients with chromosome breakage disorders. ${ }^{34}$ Their presence is generally taken as evidence of the occurrence of chromosome fragments, spindle failure, lagging chromosomes, or a failure of a chromosome to align on the spindle. ${ }^{5}$ Micronuclei are therefore thought to be present in cells that have undergone at least one nuclear division after the induction of chromosome damage. ${ }^{6}$

Although the content of micronuclei has previously been investigated (for example, antikinetochore antibodies ${ }^{47}$, only limited information is available on their content and ultrastructure. It is only with the recent advent of fluorescence in situ hybridisation (FISH), which enables a more precise investigation of the DNA content of micronuclei, ${ }^{8-10}$ that a more thorough analysis is possible.

Our interest in investigating micronuclei follows the observation that patients with the ICF syndrome (Immunodeficiency, Centromeric instability, and Facial anomalies) show an increase in the formation of micronuclei, ${ }^{11-13}$ as do other chromosome breakage disorders. ${ }^{34}$ The ICF syndrome is an extremely rare disorder, with only approximately 14 cases reported worldwide. ${ }^{13}$

It has previously been reported that the chromatin instability in the ICF syndrome is present primarily on chromosome 1 , and to a lesser extent on chromosomes 16 and 9, and appears as a decondensation of the heterochromatic regions of these chromosomes resulting in a "stretching" of the chromosomes at these regions. ${ }^{14-17}$ Multibranched forms of both chromosomes 1 and 16 have also been observed. ${ }^{14-20}$ Stretching and branching of these chromosomes is normally seen only in PHA stimulated $\mathrm{T}$ lymphocytes, is rarely seen in any other cell type, ${ }^{21}$ and may involve abnormal methylation of classical satellite $\mathrm{DNA}^{2122}$ as a contributing factor.

The observation of chromosome 1 abnormalities in ICF patients led us to speculate that the increased formation of micronuclei in these patients may be because of this chromosome lagging in the cell cycle and therefore becoming excluded as a micronucleus.

We have used an extension of "interphase cytogenetics" to investigate the chromosomal content of micronuclei in ICF patients. Probes for the classical heterochromatic regions of chromosomes 1 and 16, and an alpha satellite probe for chromosome 9 are used to show involvement of the abnormal chromosomes specific to this syndrome with the high incidence of micronuclei observed. By using a technique developed in this laboratory, ${ }^{23}$ direct observations on the content of micronuclei in vivo were also made.

\section{Materials and methods}

PATIENTS

Patients ICFMB and ICFCC were referred for cytogenetic analysis following the diagnosis of 
variable immunodeficiency. A blood sample from ICFCU was kindly donated by $\operatorname{Dr} A$ Tukun (Department of Medical Biology, University of Ankara, Turkey).

\section{CELl PREPARATION}

Triplicate cultures of PHA stimulated peripheral blood from patient ICFMB and five controls were established following standard protocols. Briefly, $0.2 \mathrm{ml}$ of whole peripheral blood was incubated in $5 \mathrm{ml}$ of RPMI medium supplemented with $10 \%$ FCS and PHA. Cultures were grown for a total of 48 hours, with colcemid added only for the final 15 minutes. Cells were treated with $0.075 \mathrm{~mol} / 1 \mathrm{KCl}$ for 10 minutes, before fixation in 3:1 methanol/acetic acid. The cell suspensions were dropped onto clean slides and the area marked before storing at $-20^{\circ} \mathrm{C}$. Triplicate cultures were also established using pokeweed mitogen to stimulate $B$ cell division in both patient 1 and controls.

Peripheral blood smears: $5 \mu \mathrm{l}$ of whole peripheral blood from a second patient (ICFCU) and five controls were smeared along the length of clean microscope slides. Slides were air dried, fixed in 3:1 methanol/acetic acid, and stored at $-20^{\circ} \mathrm{C}$

An Epstein Barr virus (EBV) transformed lymphoblastoid cell line (LCL) of a further patient (ICFMK) was kindly donated by Dr P Kieback. ${ }^{24}$ Control LCLs established from normal subjects were donated by Dr M Taylor, Institute of Cancer Research, Birmingham University. Colcemid was added to actively growing cultures for five minutes before treating with $0.075 \mathrm{~mol} / 1 \mathrm{KCl}$ for 10 minutes. Cells were fixed in 3:1 methanol/acetic acid before dropping onto clean slides.

\section{ANALYSIS OF MICRONUCLEI}

The methods used to examine micronuclei are essentially those described by Sternes and $\mathrm{Vig}^{5}$ and Heddle et al. ${ }^{25}$ Randomly selected cultured interphase cells were scored for associated micronuclei. Blood smears yielded relatively few cells so all associated micronuclei were noted from the material available. Micronuclei were scored as being no larger than one third the diameter of the distinct main nucleus. ${ }^{6}$

\section{DNA PROBES}

Probes for the heterochromatic regions of chromosomes 1 (pUC 1.77), ${ }^{26} 16$ (pHUR195), ${ }^{27}$ and the chromosome 9 specific alphoid probe pMR9A ${ }^{28}$ were used to identify these regions by FISH. Specific heterochromatic inserts were labelled by PCR using universal M13 primers after optimal PCR conditions were established for each probe; $1 \mu \mathrm{l}$ of PCR product was then used in a second PCR reaction in the presence of fluorescein-12-dUTP (FITC) or hydroxycoumarin-6-dUTP (Boehringer Mannheim) to label the DNA insert directly. A directly labelled 18 centromere specific alphoid probe (Chromoprobe $18^{\mathrm{TM}}$; Cytocell Ltd), not associated with the ICF syndrome, was used as a control.
FLUORESCENCE IN SITU HYBRIDISATION (FISH)

Slides were denatured through an ethanol series (70, 85, and $100 \%$ ethanol), air dried, and warmed to $37^{\circ} \mathrm{C}$. A total of $10 \mu \mathrm{l}$ of hybridisation fluid $(7 \mu \mathrm{l} 50 \%$ formamide, $2 \times$ SSC, $10 \%$ dextran sulphate solution, $2 \mu \mathrm{l}$ $\mathrm{dH}_{2} \mathrm{O}, 1 \mu \mathrm{l}$ labelled PCR product), also prewarmed to $37^{\circ} \mathrm{C}$, was added to the marked area of the slide and a coverslip placed over the hybridisation mix to ensure even distribution. The edges of the coverslip were sealed with rubber solution to prevent evaporation. Denaturation of the probe and cells was performed simultaneously by placing the slides on a hot block, preset to $76^{\circ} \mathrm{C}$, for five minutes. Slides were quickly returned to $37^{\circ} \mathrm{C}$ and incubated in the dark overnight.

Slides were washed through $50 \%$ formamide/ $2 \times \operatorname{SSC}(3 \times), 2 \times \operatorname{SSC}(1 \times)$, and $4 \times \mathrm{SSC} /$ $0.05 \%$ Tween $(1 \times)$, all at $45^{\circ} \mathrm{C}$, and $4 \times$ SSC/ $0.05 \%$ Tween $(1 \times)$ at room temperature (five minutes each) before counterstaining with $0.7 \mu \mathrm{g} / \mathrm{ml}$ propidium iodide in Vectashield antifade solution (Vector Labs). Hybridisation signals were observed using a Nikon Labophot-2 fluorescence microscope with filter sets UV2A (AMCA) and B1A (FITC). Chromoprobe $18^{\mathrm{TM}}$ was hybridised according to the manufacturer's protocol.

\section{Results}

IN SITU HYBRIDISATIONS ON METAPHASE CHROMOSOMES

Three hundred and three randomly selected metaphases from PHA stimulated peripheral blood lymphocytes were examined for the characteristic "stretching" and "branching" of the chromosome regions $1 \mathrm{qh}, 9 \mathrm{qh}$, and $16 \mathrm{qh}$ in ICFMB. Of the cells examined, $92(30 \%)$ showed elongation of the heterochromatic block of chromosome 1 (fig 1A), with seven cells $(2 \%)$ also showing multibranching (fig 1B). Fig 1C shows a multibranched and fragmented chromosome 1 within the same metaphase. Three cells $(1 \%)$ showed stretching of the heterochromatic region of chromosome 16 and one cell showed a multibranched chromosome 16. Although the probe pMR9A detects alphoid sequences, no stretching or branching of chromosome $9 \mathrm{qh}$ was observed in this patient. No stretching or branching of the heterochromatic regions of chromosomes 1 , 9 , or 16 were observed in five normal controls.

No metaphase spreads were obtained from any cultures using pokeweed mitogen to stimulate $\mathrm{B}$ cell division.

Three hundred and sixty two metaphase chromosomes were also examined in an LCL from patient ICFMK. No abnormalities in the heterochromatic regions of chromosomes 1,9 , or 16 were observed in this patient, or in three normal control cell lines.

\section{IN SITU HYBRIDISATIONS ON MICRONUCLEI} Peripheral blood cultures

Initial observations on the significantly raised levels of micronuclei in an ICF patient (ICFCC) were made some time before this 

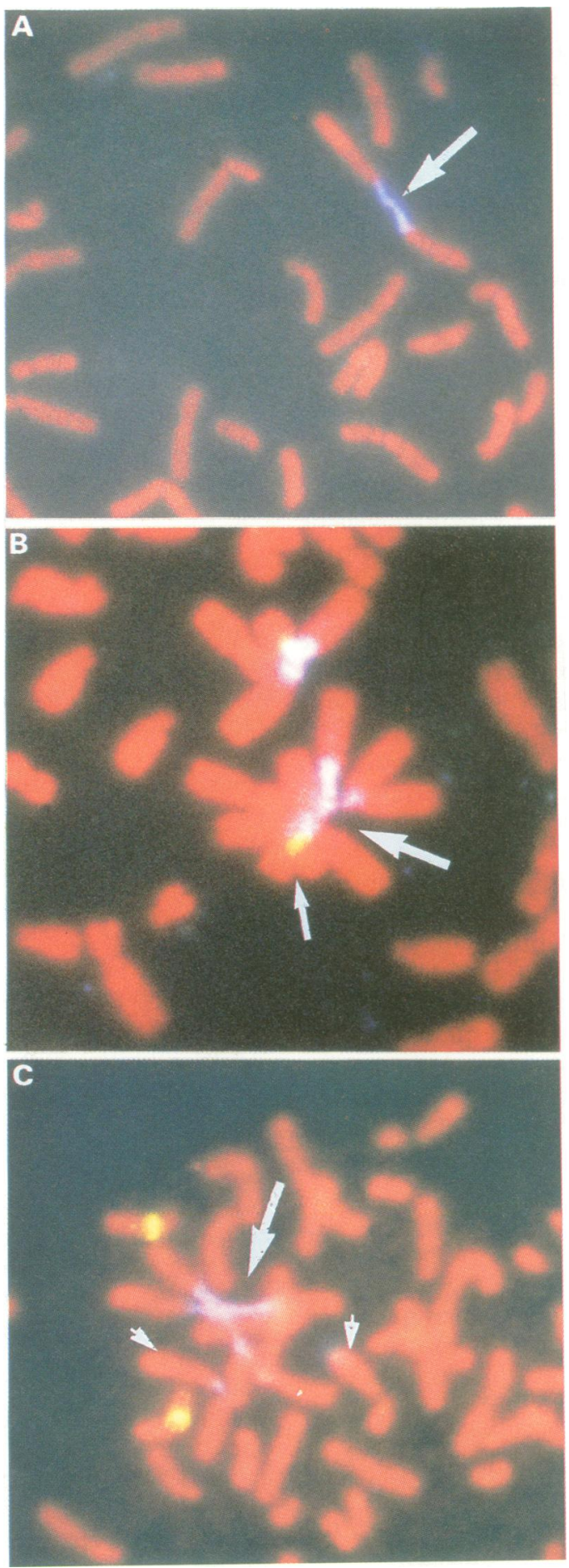

Figure 1(A) A partial metaphase showing decondensed 1 qh (arrowed) labelled with the chromosome 1 specific heterochromatic probe pUC 1.77. (B) A multibranched chromosome 1 (blue 1qh, large arrow) in association with 16ah (yellow, small arrow). (C) Partial metaphase showing a multibranched chromosome 1 (large arrow) and a fragmented chromosome 1 (small arrows).

Table 1 Percentage of micronuclei (No) present in peripheral blood cultures showing hybridisation signals for chromosomes 1,9 , and 16

\begin{tabular}{|c|c|c|c|c|c|c|}
\hline \multirow[t]{2}{*}{ Sample } & \multirow[t]{2}{*}{$\begin{array}{l}\text { Micronucleil } \\
1000 \text { cells }\end{array}$} & \multicolumn{5}{|c|}{$\begin{array}{l}\text { \% Hybridisation present in micronuclei from PHA stimulated peripheral } \\
\text { blood cultures (No of micronuclei) }\end{array}$} \\
\hline & & $1 q h$ & 9 cen & $16 q h$ & No signal & $18 \mathrm{cen}$ \\
\hline $\begin{array}{l}\text { ICFMB } \\
\text { Con } 1 \\
\text { Con } 2 \\
\text { Con } 3\end{array}$ & $\begin{array}{r}25 \\
0 \\
2 \\
0\end{array}$ & $\begin{array}{l}42(13) \\
0 \\
0 \\
0\end{array}$ & $\begin{array}{l}6(2) \\
0 \\
0 \\
0\end{array}$ & $\begin{array}{c}10 \\
0 \\
0 \\
0\end{array}$ & $\begin{array}{c}42(13) \\
0 \\
100(2) \\
0\end{array}$ & $\frac{0 / 10 \mathrm{Mn}}{0}$ \\
\hline
\end{tabular}

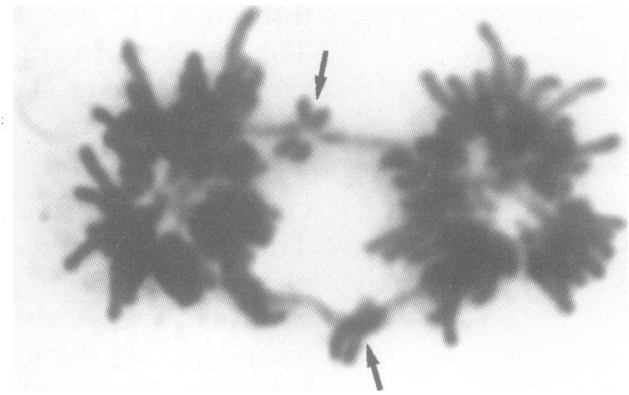

Figure 2 Giemsa stained lymphocyte division at anaphase showing two "lagging" chromosomes (arrowed).

study. From 1000 randomly selected nuclei, 58 micronuclei $(5 \cdot 8 \%)$ were observed in ICFCC compared to $10(1 \%)$ in an age/sex matched control in 72 hour PHA stimulated blood cultures $\left(\chi_{1}^{2}=230, p<0 \cdot 001\right)$.

Interestingly, in lymphocytes from the same patient fixed at anaphase, large metacentric chromosomes were observed which were "lagging" behind the remaining chromosomes (fig $2)$. This phenomenon was not observed in control cultures.

Table 1 summarises the data obtained for micronuclei examined by FISH from PHA stimulated peripheral blood cells of a second ICF patient (ICFMB) and three normal controls. The number of micronuclei $(\mathrm{Mn})$ present in 1000 observed nuclei is large $(2.5 \%)$ compared to the three controls examined $(0 \%$, $0.2 \%$, and $0 \%$ for Con 1,2 , and 3 respectively) $\left(\mathrm{X}^{2}{ }_{1}=883, \mathrm{p}<0.001\right)$. Of the 1251 cells observed in ICFMB following FISH, $31 \mathrm{mi}-$ cronuclei were counted. Forty two percent $(13 \mathrm{Mn})$ showed a positive signal for the heterochromatic region of chromosome 1 (fig $3 \mathrm{~A}$ ) (including four micronuclei with two hybridisation signals/micronucleus (fig 3B)), $6 \%$ (two $\mathrm{Mn}$ ) for chromosome 9 , and $10 \%$ (three $\mathrm{Mn})$ for $16 \mathrm{qh}$. Forty two percent (13 Mn) showed no hybridisation signal. Of these micronuclei showing a hybridisation signal, a significant proportion contained a signal for $1 \mathrm{qh}$ $\left(\chi_{1}^{2}=8 \cdot 2, \mathrm{p}=0.005-0.001\right)$ compared to chromosome $9\left(\chi_{1}^{2}=2 \cdot 7, \mathrm{p}=0 \cdot 1\right)$ or $16 \mathrm{qh}\left(\chi_{1}^{2}=\right.$ $1 \cdot 5, \mathrm{p}=0 \cdot 3-0 \cdot 2)$.

No signals from chromosomes 1qh, 9, or $16 \mathrm{qh}$ were observed in two micronuclei from Con 2 (1000 cells examined), or from an extra 10 micronuclei examined in ICFMB using an 18 centromeric probe. This signal was found only in the main nucleus.

\section{Peripheral blood smears}

Hybridisation signals were also detected in micronuclei from ICFCU. In this case the micronuclei were observed in peripheral blood smears, although very few cells were present. Of 81 cells examined, four micronuclei were observed, two showing a single signal for $1 \mathrm{qh}$ and two for chromosome 9 . No micronuclei were observed in five control blood smears. 
Table 2 Percentage of micronuclei (No) present in EBV transformed lymphoblastoid cell lines showing hybridisation signals for chromosomes 1,9 , and 16

\begin{tabular}{lllllll}
\hline Sample & $\begin{array}{l}\text { Micronucleil } \\
1000 \text { cells }\end{array}$ & \multicolumn{3}{l}{$\begin{array}{l}\text { \% Hybridisation present in micronuclei from } \\
\text { lines (No of micronuclei) }\end{array}$} \\
\cline { 3 - 7 } & & $1 q h$ & 9 cen & $16 q h$ & No signal & 18 cen \\
\hline ICFMK & 36 & $20(47)$ & 0 & $3(7)$ & $77(183)$ & $0 / 50 \mathrm{Mn}$ \\
Con A & 4 & 0 & $14(3)$ & $5(1)$ & $81(17)$ & $0 / 50 \mathrm{Mn}$ \\
Con B & 5 & 0 & 0 & $8(3)$ & $92(32)$ & - \\
Con C & 8 & $5(2)$ & 0 & $5(2)$ & $90(40)$ & - \\
\hline
\end{tabular}
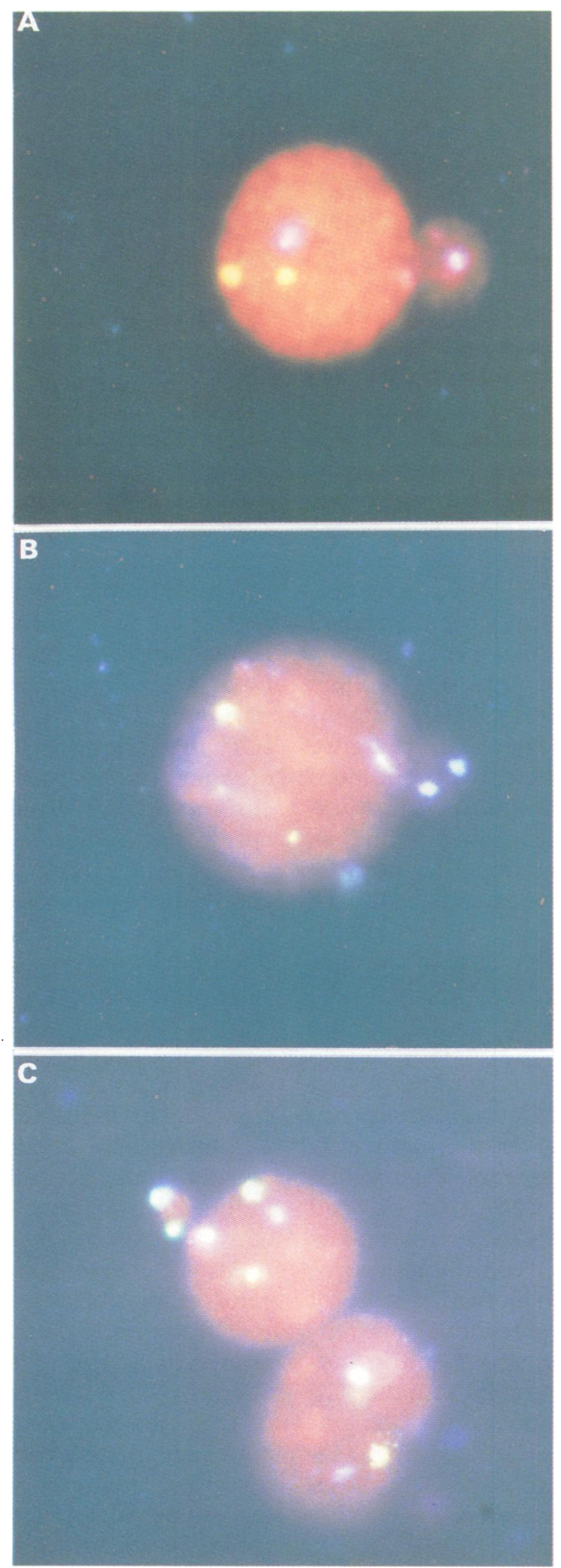

Figure 3 (A) Micronucleus with a single hybridisation signal for 1qh (blue). The main nucleus contains one signal for 1qh (blue) and two signals for 16qh (yellow).

(B) Micronucleus containing two hybridisation signals for 1qh. The main nucleus contains two signals for $16 \mathrm{gh}$ (yellow). (C) A micronucleus from ICFMK showing hybridisation signals for both 1qh (blue) and 16qh (yellow). The main nucleus also contains two signals each of 1 qh and 16qh.
Lymphoblastoid cell lines

Table 2 summarises the data obtained from an LCL established from patient ICFMK. The number of micronuclei observed/1000 cells is high $(3.6 \%)$ compared to three normal control lines $(0.4 \%, 0.5 \%$, and $0.8 \%$ for Con $A, B$, and $C$ respectively) $\left(\chi_{1}^{2}=161, p<0.001\right)$. The number of micronuclei present in all LCLs, whether ICF or controls, is higher than the numbers observed in PHA stimulated lymphocytes (table 1). However, the number of micronuclei observed in the LCL ICFMK is not significantly higher than those in the nontransformed cells (ICFMB) $\left(\chi^{2}{ }_{1}=4 \cdot 84, p=\right.$ $0.05-0.02)$, whereas in the control LCLs there is a significant increase in the number of micronuclei compared to non-transformed cells $\left(\chi_{1}^{2}=37 \cdot 76, \mathrm{p}<0.001\right)$.

Of the 6500 cells observed following FISH, 237 micronuclei were counted. Of these micronuclei, $20 \%(47 \mathrm{Mn})$ showed a signal for chromosome 1qh, none showed a signal for chromosome 9 and 3\% (seven $\mathrm{Mn}$ ) showed a signal for chromosome 16qh. Seventy seven percent $(183 \mathrm{Mn})$ showed no hybridisation signal. Of these micronuclei showing a hybridisation signal, a significant proportion contained a signal for $1 \mathrm{qh} \quad\left(\chi^{2}{ }_{1}=46 \cdot 7\right.$, $\mathrm{p}<0.001)$ compared to $16 \mathrm{qh}\left(\chi_{1}^{2}=6 \cdot 7, \mathrm{p}=\right.$ $0.01-0.005)$ and chromosome 9 , which was significantly under-represented $\left(\chi_{1}^{2}=18\right.$, $\mathrm{p}<0.001)$. As with PHA stimulated blood cultures, micronuclei containing more than one signal were also observed although, like ICFMB, the number was low (two $\mathrm{Mn}$, both showing signals for $1 \mathrm{qh}$ and 16qh). Fig 3C shows a micronucleus (from ICFMK) with signals for both chromosomes $1 \mathrm{qh}$ and $16 \mathrm{qh}$, even though the main nucleus contains two signals each for these chromosomes.

In the control cell lines, the majority of micronuclei contained no signal $(81 \%, 92 \%$, and $90 \%$ for Con A, B, and C respectively) (table 2) which was not significantly different from the numbers observed in the LCL ICFMK $(77 \%)\left(\chi_{1}{ }_{1}=1 \cdot 30, p=0 \cdot 3-0 \cdot 2\right)$. Unlike nontransformed cells, the three control LCLs showed a small number of micronuclei with signals for 1qh (Con C 5\% (two Mn)), 9 (Con A $14 \%$ (three $\mathrm{Mn}$ )), and 16qh (Con A 5\% (one Mn), Con B 8\% (three Mn), and Con C $5 \%$ (two $\mathrm{Mn}$ )).

An 18 centromeric probe gave no signal in 50 extra micronuclei examined in both ICFMK and Con A. The signal was always present in the main nucleus.

\section{Discussion}

METAPHASES

Metaphases were initially examined from PHA stimulated cultures to confirm the presence of the characteristic stretching and branching of the heterochromatic regions observed in ICF patients. The levels obtained, although low compared to others, ${ }^{16}$ were consistent with abnormalities observed in other ICF patients. ${ }^{15}$

Interestingly, a lymphoblastoid B cell line established from ICFMK ${ }^{24}$ showed no ab- 
normalities of the heterochromatic regions of chromosome 1, 9, or 16. Other workers have found that these abnormalities also occur only in PHA stimulated cultures compared to fibroblasts or lymphoblastoid cell lines. ${ }^{21} \mathrm{Un}$ fortunately we were unable to make a direct comparison on different cell types from the same patient. Stimulation of B cells by pokeweed mitogen is very inefficient and yielded no mitosis from ICFMB or control peripheral blood cultures.

\section{MICRONUCLE}

\section{Peripheral blood cultures}

The number of micronuclei observed from PHA stimulated blood cultures from ICFMB was increased compared to three controls (table 1), and of those micronuclei showing a hybridisation signal a large proportion were specific for $1 \mathrm{qh}$, suggesting that micronuclei were formed from stretched/branched chromosomes 1. An equal proportion of micronuclei also showed no hybridisation signal, although the main nuclei did, indicating that the lack of signal was not a result of non-hybridised areas.

The numbers of micronuclei with signals for chromosomes 9 or 16 were significantly lower than those for chromosome 1, but the abnormalities observed in metaphases was also lower. It is possible that the chromosome 9 abnormalities observed in metaphases are artificially low as the probe used was alphoid specific and therefore did not detect less obvious decondensations of $9 \mathrm{qh}$. The presence of chromosome 9 shows that this probe does detect exclusion of this chromosome into micronuclei. Signals for chromosomes 9 and 16 were, however, still higher than the number of micronuclei observed with signals for 18 centromere, suggesting that those chromosomes showing an abnormality in the heterochromatic regions are more likely to be excluded into micronuclei.

Interestingly, a recent paper by Guttenbach and $\mathrm{Schmid}^{29}$ noted that 5-azacytidine treated cultures also show an increase in the frequency of micronuclei, and that these predominantly contain signals for the heterochromatic regions of chromosomes $1,9,16,15$, and Y. 5-azacytidine induces characteristic undercondensation in the late replicating heterochromatic regions ${ }^{30}$ by hypomethylation of incorporated cytidine analogues. The same pattern of hypomethylation is also noted in heterochromatic DNA from patients with the ICF syndrome. ${ }^{2122}$ It therefore appears that the heterochromatic abnormalities induced by 5 -azacytidine (5-Aza) in cultured lymphocytes is an experimental phenomenon mirrored in specific chromosomes of ICF patients.

There is a high degree of concurrence between the results obtained here from ICF patients, and those obtained in 5-azacytidine treated lymphocyte cultures by Guttenbach and Schmid. ${ }^{29}$ Firstly, an increase in the micronuclei frequency was obtained $(2 \cdot 5 \%$ and $1 \cdot 5 \%-2 \cdot 0 \%$ for ICFMB and 5-Aza cultures respectively) and, secondly, the number of micronuclei showing a signal for 1qh was approximately $40 \%$ in both cases. In the 5-Aza treated cultures more micronuclei were observed with signals for chromosome 9 (ICFMB 6\%, 5-Aza 20\%) and chromosome 16 (ICFMB 10\%, 5-Aza $16 \%$ ) but this may be because 5 -azacytidine is more effective at decondensing the heterochromatic regions of all chromosomes in vitro compared to the levels observed spontaneously in ICF metaphases, where chromosome 1 is predominantly decondensed. Also in agreement with our results is that no signal was found in micronuclei using examples of probes not associated with the ICF syndrome (18 cen here and 11, 17, and X cen in 5-Aza cultures). The results for ICFMB are also in broad agreement with those obtained by Maraschio et al. ${ }^{11}$ In two ICF patients observed, a frequency of $6 \cdot 7 \%$ and $10 \cdot 3 \%$ of cells showed nuclear anomalies (micronuclei and cell protrusions), although here all nuclear anomalies contained FISH signals for chromosomes 1 and 16 using the probe pHUR 195. Although this difference appears large compared to the values described in ICFMB, this may be because of a number of reasons, including variability in both patients and protocol.

It would be of interest to examine the "empty" micronuclei observed in ICF patients by chromosome paints for chromosomes 1,9 , and 16, as experimentally induced decondensation of the heterochromatic regions by 5 -azacytidine also causes fragmented chromosomes. ${ }^{30}$ These are also occasionally seen in ICF metaphases ${ }^{31}$ (fig 1C). ${ }^{31}$ A proportion of micronuclei may contain fragments of chromosomes 1,9 , or 16 without the heterochromatic regions being present. Chromosomes 15 and $\mathrm{Y}$ also contain heterochromatic regions sensitive to the decondensing effects of 5- azacytidine. A number of empty micronuclei observed in ICFMB may also possibly contain these chromosomes. Formation of micronuclei with decondensed heterochromatic regions suggests that these chromosomes are not in phase with the cell cycle resulting in their exclusion as micronuclei, ${ }^{32}$ although there is no reported evidence at present that decondensed heterochromatin induced by 5 -azacytidine also shows lagging chromosomes as observed in ICFCC (fig 2).

Also of interest would be the examination of gene expression near the decondensed heterochromatin regions. It is a well known phenomenon that expression of nearby genes is altered by the change in methylation status of the heterochromatic regions. ${ }^{33}$ It could be envisaged that deregulation of specific genes owing to hypomethylation may have some bearing on the ICF phenotype. In this respect, a recent paper by Miniou et $a l^{22}$ is of interest. Here they report abnormal methylation patterns in both the inactive $\mathrm{X}$ chromosome and the constitutive heterochromatin in ICF patients using monoclonal antibodies against 5-methylcytosine, and have shown that genes normally inactive and methylated on the inactive $\mathrm{X}$ chromosome are hypomethylated in the ICF syndrome. 


\section{Peripheral blood smears}

An important observation from peripheral blood smears from ICFCU is that the micronuclei present here also contain signals from the heterochromatic region of chromosome 1 and the centromere of chromosome 9. Although the number of micronuclei observed was low, we feel that examination of micronuclei from peripheral blood smears gives an accurate representation of the condition in vivo $^{23}$ and is not therefore the result of culture conditions.

\section{Lymphoblastoid cell lines}

Although there is not a statistically significant increase in the number of micronuclei present in the LCL ICFMK compared to the nontransformed ICFMB, more observations were possible as the total number of main nuclei present was increased. No heterochromatic abnormalities were observed in metaphases from the LCL derived from ICFMK, yet paradoxically, micronuclei present continue to show an increased involvement of chromosome 1. This suggests that chromosome 1 is also preferentially segregated into micronuclei in ICF $B$ cell lines. If the characteristic stretching and branching observed in $\mathrm{T}$ cells is responsible for the formation of micronuclei, they may well therefore be present at very low levels in LCLs and other tissues. One group has reported stretched heterochromatic regions in fibroblasts from an ICF patient, ${ }^{15}$ and another has observed stretched 1 qh in an EBV transformed cell line. ${ }^{16}$ However, these results are considered to be an exception as these chromosomal abnormalities are almost exclusively seen in PHA stimulated lymphocytes. ${ }^{213435}$ Mechanisms involved in B cell transformation may destabilise the cell in such a way that the formation of micronuclei is increased, as seen in the control LCLs. Since ICF cells already appear to "predispose" to the formation of micronuclei, it is possible that there would be no significant increase in the number of micronuclei following EBV transformation, and that a significant number of micronuclei retain a signal for $1 \mathrm{qh}$. This "predisposition" to the formation of micronuclei may be slightly enhanced by the transformation process, resulting in an increase in micronuclei with no hybridisation signal, similar to the levels observed in control LCLs, yet still retaining the high levels of micronuclei with a signal for $1 \mathrm{qh}$, although now at a relatively low level.

Examination of micronuclei may still give a clearer picture of the underlying frequency of heterochromatic abnormalities and indicate that 1 gh abnormalities in B cells occur at a higher frequency than otherwise might be expected from metaphase observations. There may be an underlying mechanism responsible for exclusion of chromosomes into micronuclei which may be manifest at the cytogenetic level only in specific cell types (for example, $\mathrm{T}$ cells), and not in other different cell lineages. Sabry and Hulten ${ }^{36}$ have reported that heterochromatin in $\mathrm{T}$ cells decondense more readily in the presence of low concentrations of 5- azacytidine compared to B cells ${ }^{36}$ or skin fibroblasts. ${ }^{37}$ This differential effect between different cell types may explain why the number of micronuclei with a signal for $1 \mathrm{qh}$ in the LCL ICFMK is not observed at the cytogenetic level.

Recent advances have now made it possible to immunophenotype individual cells and thus identify particular subsets of cells with specific abnormalities. ${ }^{38}$ For example, it has been shown that there is an increased frequency of micronuclei in B and T8 cells in smokers. ${ }^{39}$ It would be of interest to determine whether micronuclei formed in the ICF syndrome occur only in a particular subset of $\mathrm{T}$ or B cells and how this relates to the observed immunodeficiency in these patients.

ICF is a very rare disorder and therefore it was not possible to investigate all aspects together in one patient in this study. The observations here, however, do show the importance of the content of the micronuclei in relation to the chromosome structure. By investigating other disorders with an increased spontaneous frequency of micronuclei, it may be possible to elucidate problems observed at the cellular level with their micronuclei content.

This work was supported by the Leverhulme Trust. I would also like to thank Clare Pullar for excellent technical assistance and Drs $M$ Lawrie and $T$ Webb for helpful discussion.

1 Ellard S, Parry EM. Induction of micronuclei in V79 Chinese Hamster cells by hydroquinone and econazole nitrate. Mutat Res 1993;287:87-91.

2 Majone F, Semmes OJ, Jeang KY. Induction of micronucle by HTLV-1 Tax - a cellular assay for function. Virology 1993;193:456-99.

3 Rosin MP, German J. Evidence for chromosome instability in vivo in Bloom's syndrome: increased numbers of micronuclei in exfoliated cells. Hum Genet 1985;71:187-91.

4 Hennig UGG, Rudd NL, Hoar DI. Kinetochore immunofluorescence in micronuclei: a rapid method for the in situ detection of aneuploidy and chromosome breakage in human fibroblasts. Mutat Res 1988;203:405-14.

5 Sternes KL, Vig BK. Micronuclei, kinetochores and hypoploidy: tests with some agents. Mutagenesis 1989;4: poploidy:

6 Ren L, Zhang H, Yang J, Zhang Z. A sequential study on the use of the cytokinesis block micronucleus method in the use of the cytokinesis block micronucleus m
mouse splenocytes. Mutat Res 1993;301:223-7.

7 Yager JW, Eastmond DA, Robertson ML, et al. Characterisation of micronuclei induced in human lymphocytes by benzene metabolites. Cancer Res 1990;50:393-9.

8 Titenko-Holland N, Moore LE, Smith MT. Measurement and characterisation of micronuclei in exfoliated human cells by fluorescence in situ hybridisation with a centromeric probe. Mutat Res 1994;312:39-50.

9 Becker P, Scherthan H, Zanki H. Use of a centromere specific DNA probe ( $\mathrm{p} 8 \mathrm{ZH})$ in non-isotopic ISH for classification of micronuclei. Genes, Chromosomes and Cancer 1990;2:59-62.

10 Miller BM, Nusse $M$. Analysis of micronuclei induced by 2-chlorobenzylidene malonitrile (CS) using fluorescence in situ hybridisation with telomeric and centromeric probes, and flow cytometry. Mutagenesis 1993;8:35-41.

11 Maraschio P, Cortinovis M, Dainotti E, et al. Interphase cytogenetics of the ICF syndrome. Ann Hum Genet 1992; 56:273-8.

12 Fasth A, Forestier E, Holmberg E, et al. Fragility of the centromeric region of chromosome 1 associated with comcentromeric region of chromosome 1 associated with com-
bined immunodeficiency in siblings. Acta Paediatr Scand bined immunodefici $1990 ; 79: 605-12$.

13 Smeets DFCM, Moog U, Weemaes CMR, et al. ICF syndrome: a new case and review of the literature. Hum Genet 1994;94:240-6.

14 Hulten M. Selective somatic pairing and fragility at $1 \mathrm{q} 12$ in a boy with common variable immunodeficiency. Clin Genet 1978;14:294.

15 Howard PJ, Lewis IJ, Harris F, Walker S. Centromeric instability of chromosomes 1 and 16 with variable immun deficiency: a new syndrome. Clin Genet 1985;27:501-5.

16 Turleau C, Cabanis M, Girault D, et al. Multibranched chromosomes in the ICF syndrome: immunodeficiency, centromeric instability and facial anomalies. $A m f \mathrm{Med}$ Genet 1989;32:420-4.

17 Tiepolo L, Maraschio P, Gimelli G, et al. Multibranched chromosomes 1,9 , and 16 in a patient with combined IgA and IgE deficiency. Hum Genet 1979;51:127-37.

18 Gimelli G, Varone P, Pezzolo A, et al. ICF syndrome with variable expression in sibs. 7 Med Genet 1993;30:429-32. 19 Valkova G, Ghenev E, Tzancheva M. Centromeric instability 
of chromosomes 1,9 , and 16 with variable immune deficiency. Support of a new syndrome. Clin Genet 1987;31: 119-24.

20 Maraschio P, Zuffardi O, Fior TD, Tiepolo L. Immunodeficiency, centromeric heterochromatin instability of chromosomes 1,9 , and 16 , and facial anomalies: the ICF syndrome. 7 Med Genet 1988;25:173-80.

21 Jeanpierre $M$, Turleau C, Aurias A, et al. An embryonic methylation pattern of classical satellite DNA is observed in the ICF syndrome. Hum Mol Genet 1993;2:731-5.

22 Miniou $P$, Jeanpierre M, Blanquet $V$, et al. Abnormal methylation pattern in constitutive and facultative ( $\mathrm{X}$ inactive chromosome) heterochromatin of ICF patients. Hum Mol Genet 1994;12:2093-102.

23 McKeown CME, Waters JJ, Stacey M, et al. Rapid interphase FISH diagnosis of trisomy 18 on blood smears. Lancet 1992;340:499.

24 Kieback P, Wendisch H, Lorenz P, Hinkel K. ICF Syndrom. Immundefizienz, chromosomale Zentromerinstabilitat, faziale Anomalien. Fallvorstellung und Literaturubersicht. Monatsschr Kinderheilkd 1992;140:91-4.

25 Heddle JA, Benz RD, Countryman PI. Measurement of chromosome breakage in cultured cells by the micronucleus technique. In: Evans, Lloyd, eds. Mutagen induced chromosome damage in man. Edinburgh: Edinburgh University Press, 1979:191-200.

26 Cooke HJ, Hindley J. Cloning of human satellite 3 DNA: different components are on different chromosomes. Nucleic Acids Res 1979;6:3177-97.

27 Moyzis RK, Albright KL, Bartholdi MF, et al. Human chromosome specific repetitive DNA sequences: novel markers for genetic analysis. Chromosoma 1987;95:375-86.

28 Rocchi M, Archidiacono N, Ward DC, Baldini A. A human chromosome 9 specific alphoid DNA repeat spatially resolvable from satellite 3 DNA by FISH. Genomics 1991; 9:517-23.

29 Guttenbach M, Schmid M. Exclusion of specific human chromosomes into micronuclei by 5 -azacytidine treatment of lymphocyte cultures. Exp Cell Res 1994;211:127-32.

30 Schmid M, Haaf T, Grunert D. 5-azacytidine-induced undercondensations in human chromosomes. Hum Genet 1984;67:257-63.

31 Carpenter NJ, Filipovich A, Blaese $M$, et al. Variable immunodeficiency with abnormal condensation of the heterochromatin of chromosomes 1,9 , and 16. $f$ Pediatr 1988;112:757-60.

32 Brinkley BR, Tousson A, Valdivia MM. The kinetochore of the mammalian chromosome: structure and function in normal mitosis and aneuploidy. In: Dellarco V, Voyteck PE, Hollaender A, eds. Aneuploidy: etiology and mechanisms. New York: Plenum Press, 1985;243-56.

33. Eden S, Cedar H. Role of DNA methylation in the regulation of transcription. Curr Opin Genet Dev 1994;4:255-9.

34 Fryns JP, Azou M, Jaeken J, et al. Centromeric instability of chromosomes 1,9 , and 16 associated with combined immunodeficiency. Hum Genet 1981;57:108-10.

35 Maraschio P, Tupler R, Dainotti E, et al. Differential expression of the ICF (immunodeficiency, centromeric heterochromatin, facial anomalies) mutation in lymphocytes and fibroblasts. $\mathcal{F}$ Med Genet $1989 ; 26: 452-6$.

36 Sabry $M$, Hulten $M$. Differential effect of the DNA analogue 5 -azacytidine on the constitutive heterochromatic blocks in $\mathrm{B}$ and $\mathrm{T}$ lymphocytes. Medical Principles and Practice. (in press).

37 Viegas-Pequignot E, Dutrillaux B. Detection of G-C rich heterochromatin by 5 -azacytidine in mammals. Hum Genet 1981;57134-7.

38 Knuutila S, Nylund SJ, Wessman M, Larramendy ML Analysis of genotype and phenotype on the same interphase or mitotic cell. Cancer Genet Cytogenet 1994;72: $1-15$.

39 Larramendy $\mathrm{ML}$, Knuutila S. Increased frequency of micronuclei in B and T8 lymphocytes from smokers. Mutat Res 1991;259:189-95. 